\title{
ALAT PANTAU JUMLAH PEMAKAIAN DAYA LISTRIK PADA ALAT ELEKTRONIK BERBASIS ARDUINO UNO
}

\author{
Agum Anantama *,1), Anisyah Apriyantina ${ }^{2)}$, S. Samsugi ${ }^{3)}$, Farli Rossi ${ }^{4)}$ \\ ${ }^{1,3,4)}$ Program Studi Teknik Elektro, Fakultas Teknik dan Ilmu Komputer, Universitas Teknokrat Indonesia \\ Jl. ZA. Pagar Alam No.9 -11, Labuhan Ratu, Bandar Lampung, Indonesia 35132 \\ ${ }^{2)}$ Program Studi Informatika, Fakultas Teknik dan Ilmu Komputer, Universitas Teknokrat Indonesia \\ Jl. ZA. Pagar Alam No.9 -11, Labuhan Ratu, Bandar Lampung, Indonesia 35132
}

Email: ${ }^{2}$ novia.utamiputri@gmail com

\begin{abstract}
This research aims to design and implement a circuit that serves to determine the amount of electricity used on a household electronic device. Tool designed to monitor this requires ACS712 and Arduino sensors. Current Sensor using ACS712 $30 A$ which serves to detect how much current is flowing. To controlling Arduino Microcontroller used $C$ and programming languages Arduino using the Arduino IDE software.The way this tool works is if people want to know the amount of usage power electronic devices that are already used quickly and concisely, users just connect the monitor to the electric current. Then the electronic devices want to be counted, associated with the contacts contained on the monitor the. Then the monitor will work and calculate the electrical power used the electronic device. After calculating the LCD will display the amount electric power used.
\end{abstract}

Keywords: ACS712 sensor, Arduino UNO, Electronics, Household, Power

\section{Abstrak}

Penelitian ini bertujuan merancang dan mengimplementasikan sebuah rangkaian yang berfungsi untuk mengetahui jumlah pemakaian daya listrik pada suatu alat elektronik rumah tangga. Alat yang dirancang untuk memantau ini membutukan sensor ACS712 dan arduino. Sensor Arus menggunakan ACS712 30A yang befungsi untuk mendeteksi berapa besar arus yang mengalir. Untuk menggontrol Mikrokontroler Arduino digunakan bahasa pemerograman $C$ dan arduino dengan menggunakan software IDE Arduino. Cara kerja alat ini adalah apabila orang ingin mengetahui jumlah pemakaian daya alat elektronik yang sudah digunakan dengan cepat dan ringkas, pengguna hanya menghubungkan alat pantau ke arus listrik. Kemudian alat elektronik yang ingin dihitung, dihubungkan dengan kontak yang terdapat pada alat pantau tersebut. Kemudian alat pantau akan bekerja dan menghitung daya listrik yang digunakan alat elektronik tersebut. Setelah dihitung lcd akan menampilkan jumlah daya listrik yang digunakan.
Kata Kunci: Arduino UNO, Daya, Rumah tangga, Sensor ACS712

\section{Pendahuluan}

Energi listrik merupakan suatu kebutuhan penting bagi manusia dan penggunaan energi listrik yang cukup banyak terdapat pada sektor rumah tangga. Penggunaan daya listrik bergantung pada pemakaian. Semakin banyak peralatan yang digunakan maka daya yang terpakai juga akan semakin besar sehingga dapat menyebabkan beban arus yang berlebih. Agar bisa melakukan manajemen listrik yang lebih baik dalam kasus rumah tangga, maka diperlukan suatu perangkat elektronika yang dapat mempermudah pekerjaan manusia dengan memanfaatkan kemajuan teknologi [1][2] dalam memonitor pemakaian energi listrik pada perangkat listrik tersebut. Tujuan penelitian ini adalah membuat alat pemantau daya listrik pada suatu alat elektronik. Hasil pengujian dilakukan dengan melihat penggunaan daya listrik pada alat elektronik yang terpantau.

Diperlukan adanya alat pantau ini yang dapat menghitung daya yang digunakan per jamnya. Alat ini mengolah arus dan tegangan yang masuk untuk diketahui berapa besar daya yg dikeluarkan. Dengan pembuatan alat ini diharapkan mempermudah para pengguna listrik rumah tangga untuk menghitung dan melakukan kalkulasi beban listrik dengan tujuan penghematan listrik yang digunakan dalam peralatan rumah tangga.

Pada penelitian pengukuran Arus telah banyak di lakukan, di antaranya perancangan dan implementasi alat ukur tegangan, arus dan frekuensi listrik arus bolak-balik satu fasa berbasis personal computer [3]. Penelitian selanjutnya yaitu Rancang Bangun Alat Ukur Arus Menggunakan Transformator Arus Berbasis Mikrokontroler Atmega32 [4]. Pada penelitian ini, telah dirancang sebuah sistem monitoring arus listrik jala-jala menggunakan Power Line Carrier (PLC). Sistem ini dapat mengetahui penggunaan arus listrik distribusi rumah tangga, sehingga jika ada penggunaan arus litrik jalajala yang berlebih, maka dapat diindikasikan pada line itu terdapat kemungkinan pencurian listrik. Sistem terdiri dari transmitter dan receiver [5]. Penelitian berikutnya membahas mengenai pengukuran daya listrik real time dengan menggunakan sensor arus acs.712 [6]. 


\section{Metode}

Penelitian dilakukan menggunakan metode eksperimen [7]. Kelancaran dalam penyusunan penelitian ini diperlukan alat \& bahan yang berhubungan dengan alat pantau daya listrik berbasis arduino, beberapa metode yang digunakan dalam memperoleh data-data tersebut, yaitu:

A. Tahapan Penelitian

Di mulai dengan Pengumpulan data yang dapat dilihat pada Gambar 1.

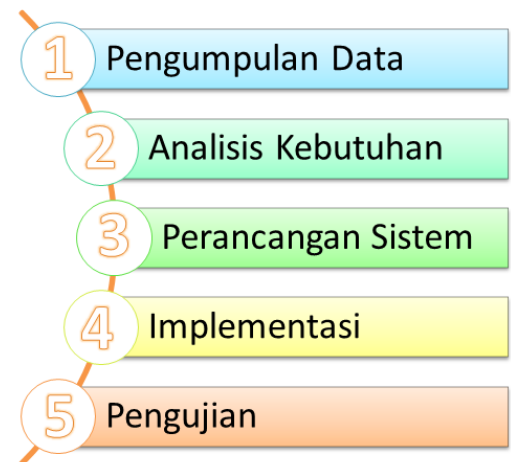

Gambar 1 Metodologi Penelitian

Pengumpulan data sebaiknya dilakukan secara teliti dan hati karena berkaitan dengan data yang akan dimasukkan kedalam system, tekniknya bisa melalui wawancara atau pengambilan data di internet[8][9].

B. Alat dan Bahan

1. Mikrokontroller Arduino adalah sebuah platform komputasi fisik open source berbasiskan Rangkain input / output sederhana (I/O) dan lingkungan pengembangan yang mengimplementasikan bahasa Processing. Arduino dapat digunakan untuk mengembangkan obyek interaktif mandiri atau dapat dihubungkan ke perangkat lunak pada komputer anda (seperti Flash, Pengolahan, VVVV, atau Max / MSP). Rangkaiannya dapat dirakit dengan tangan atau dibeli. IDE (Integrated Development Environment) Arduino bersifat open source [10].

2. LCD (Liquid Crystal Display) adalah suatu jenis media tampil yang menggunakan kristal cair sebagai penampil utama. Pada postingan aplikasi LCD yang digunakan ialah LCD dot matrik dengan jumlah karakter 16x2 . LCD sangat berfungsi sebagai penampil yang nantinya akan digunakan untuk menampilkan status kerja alat. Berdasarkan panjang data antarmuka LCD dibedakan menjadi 2 jenis yaitu, antarmuka 4 bit dan antarmuka 8 bit.

3. Sensor arus ACS712 adalah Hall Effect current sensor. Hall effect allegro ACS712 merupakan sensor yang presisi sebagai sensor arus AC atau DC dalam pembacaan arus didalam dunia industri, otomotif, komersil dan sistem-sistem komunikasi. Sensor ini memiliki pembacaan dengan ketepatan yang tinggi, karena didalamnya terdapat rangkaian low-offset linear Hall dengan satu lintasan yang terbuat dari tembaga.

\section{Perancangan Sistem}

A. Perancangan Alat

Dalam tahap perancangan terdiri dari beberapa tahapan yaitu perancangan blok diagram, diagram alir atau flow chart, alat dan bahan, hingga pada perancangan alat. B. Diagram Blok

Pada gambar diagram blok di bawah ini menjelaskan tentang cara kerja alat secara keseluruhan mulai dari input, proses, hingga output. Dalam diagram blok ini hanya terdapat hubungan jalur antara blok-blok saja, tetapi tiap masing-masing blok terdapat komponen utama dan komponen pendukung.

Pada gambar di bawah ini adalah gambar diagram blok dari alat ini.

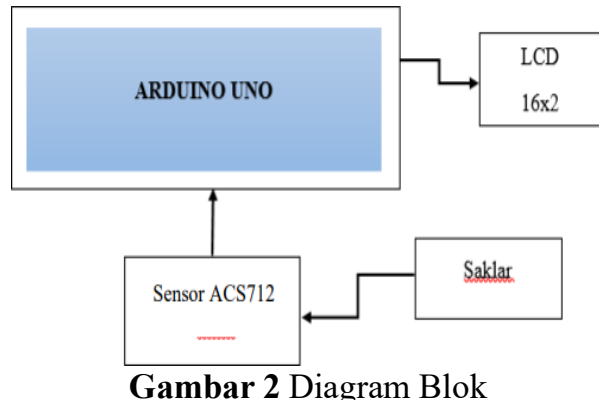

Dari blok diagram di atas dapat dijelaskan fungsi masing-masing blok sebagai berikut :

1. Mikrokontroller Arduino Uno digunakan untuk mengontrol semua komponen baik itu komponen input dan komponen output. Sensor ACS712

2. Lcd 16x2 karakter berfungsi sebagai alat penampil yang nantinya akan digunakan untuk menampilkan status kerja alat.

3. Sensor ACS712 berfungsi untuk mendeteksi besar arus yang mengalir lewat blok terminal.

4. Saklar sebagai penghubung alat elektronik pada tengangan listrik.

C. Perancangan Keseluruhan Alat

Perancangan rangkaian keseluruhan alat terdiri dari empat elemen penting yang saling terintegrasi. Elemen-elemen penting tersebut yaitu rangkaian input, rangkaian pengendali, rangkaian output dan juga software program yang saling terintegrasikan.

Berikut gambar perancangan alat untuk alat pantau dapat dilihat pada Gambar 3. 


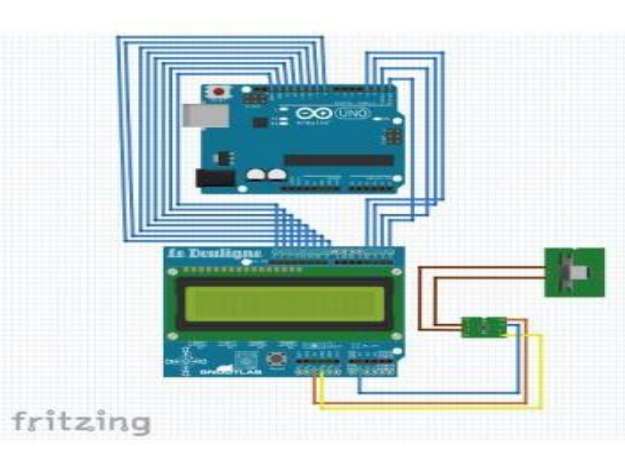

Gambar 3 Perancangan Alat

Perancangan sistem pada software Arduino sangat lah penting sebab dari sinilah program dibuat dan di upload mengunakan software Arduino, hal ini bertujuan untuk menyisipkan kode program kedalam Arduino, berikut ini adalah inisialisasi program arduino mengunakan Arduino Uno seperti yang di tunjukan oleh gambar di bawah ini :

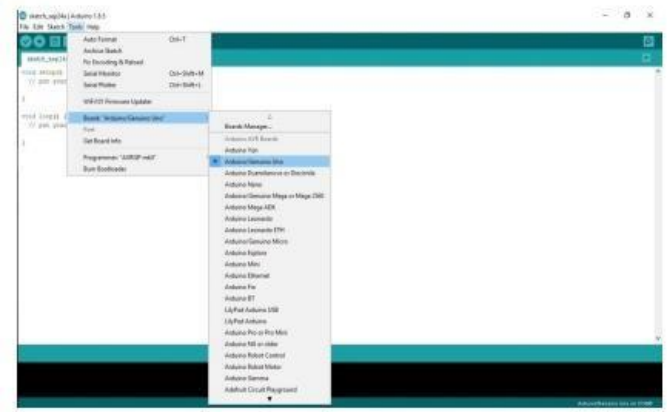

Gambar 4 Inisialisasi jenis Arduino pada IDE Arduino

Selain langkah di atas kita juga perlu menginisialkan Port Serial tujuannya agar Arduino dapat terhubung ke komputer biasanya mengunakan sebuah kabel USB agar Arduino dapat terhubung dengan komputer. Berikut ini adalah contoh penginisialan Port Arduino pada Software IDE Arduino.

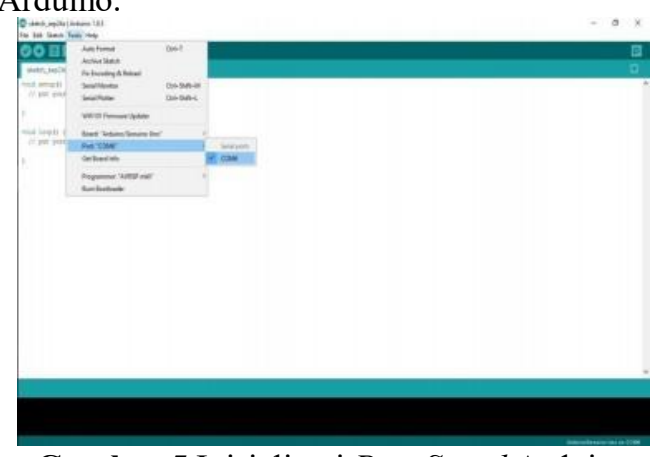

Gambar 5 Inisialisasi Port Serial Arduino

D. Penulisan Kode Program

Penulisan kode program dilakukan untuk memberikan instruksi-instruksi mengunkan bahasa pemrograman $\mathrm{C}$ yang bertujuan untuk menjalankan sistem agar dapat berkerja sesuai kode program yang telah diisikan kedalam sebuah Arduino. Berikut ini adalah tampilan layer untuk mengisikan kode program pada Software IDE Arduino.

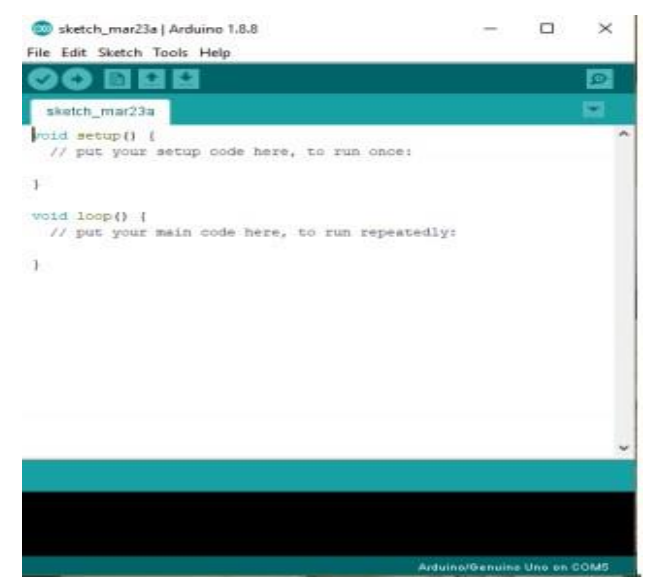

Gambar 6 Layer Penulisan Sketch Program

\section{E. Diagram Alir}

Flowchart program perangkat keras menggambarkan bagaimana alur dari pembacaan program pada mikrokontroler yang difungsikan untuk membaca nilai sensor [11]. Pada diagram alir di bawah ini menjelaskan tentang bagaimana cara kerja dan proses alat bekerja:

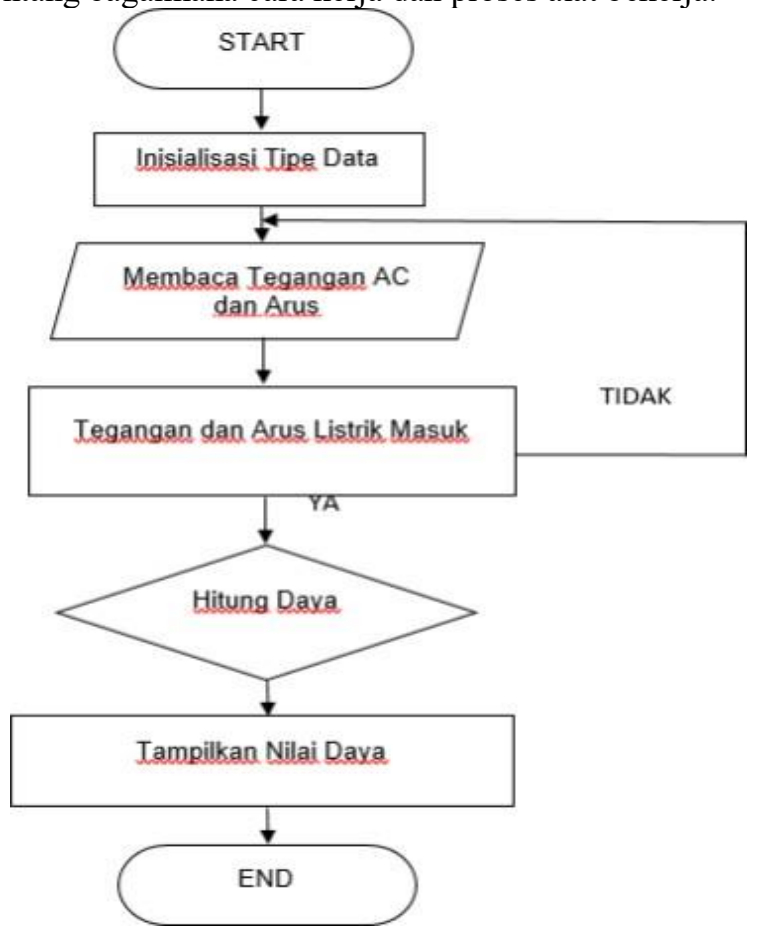

Gambar 7 Diagram alir proses kerja alat

F. Alat dan Bahan

Dalam pembuatan alat tugas akhir ini memerlukan beberapa komponen dan bahan. Komponen dan bahan yang digunakan dalam pembuatan alat ini adalah:

1. Alat

a. Komputer/Laptop

Digunakan untuk pembuat program, memeriksa program, dan mengupload program ke dalam Mikrokontroller Arduino Uno.

b. Multitester

Multitester adalah alat ukur listrik yang dapat mengukur besaran nilai komponen 
elektronika. Selain itu multitester juga digunakan untuk mengetahui keadaan sebuah komponen.

c. Solder

Solder adalah alat yang digunakan untuk menyolder terminal (kaki) komponen elektronika sehingga menyatu dengan papan rangkaian (PCB) dengan menggunakan timah

d. Penyedot Timah / Solder Sucker

Penyedot timah atau solder sucker merupakan perlatan yang berfungsi untuk menyedot timah yang dilelehkan dengan solder ketika akan melepas komponen elektronika. Penyedot timah ini sangat berguna bagi seorang teknisi ketika akan melepas komponen yang rusak untuk diganti dengan komponen baru, karena mengingat pada umumnya komponen yang telah tersolder susah diangkat dengan tanpa menghilangakan terlebih dahulu timah yang merekatkannya.

e. Obeng

Obeng digunakan untuk memasang mur dan baut dalam proses pembuatan alat ini.

f. Saklar

Saklar berfungsi untuk memutuskan atau menyambungkan suatu rangkaian, bisa itu rangkaian listrik maupun rangkaian elektronika.

2. Bahan

Bahan-bahan yang dibutuhkan dalam pembuatan alat ini dapat dilihat pada

Tabel 1 seperti berikut :

Tabel 1 Bahan yang digunkan

\begin{tabular}{|r|c|c|}
\hline No & Nama Komponen & Jumlah \\
\hline 1 & Arduino UNO & 1 \\
\hline 2 & Lcd 16x2 & 1 \\
\hline 3 & Kabel Jumper & 3 \\
\hline 4 & Solder & 1 \\
\hline 5 & Timah & Secukupnya \\
\hline 6 & Sensor ACS712 & 1 \\
\hline
\end{tabular}

\section{Pengujian dan Analisa}

Sistem pengontrol irigasi secara otomatis dibangun menggunakan Arduino UNO (sebagai pusat kontrol), sensor ultrasonik HCSRF-04 (sebagai pendeteksi debit air), serta beberapa komponen elektronika lainnya (sebagai penunjang kesatuan alat). Alat yang telah dibangun dapat dilihat pada Gambar 7.

Pengujian alat dilakukan untuk mengetahui apakah fungsi-fungsi yang telah direncanakan bekerja dengan baik atau tidak [12]. Pengujian pada alat ini meliputi pengujian setiap blok maupun pengujian secara keseluruhan. Pengujian setiap blok ini dilakukan untuk menentukan letak kesalahan dan mempermudah dalam analisa bila alat tidak bekerja sesuai rancangan.

\section{A. Pengujian Alat}

Dalam pengujian alat akan dibahas tentang pengujian bedasarkan perencanaan dari mikrokontroler yang dibuat dan pengujian yang dilakukan sesuai dengan perencanaan yang dibahas. Mula-mula pengujian dilakukan dengan terpisah, mulai dari komponen- komponen yang digunakan dalam perancangan alat ini sehingga mendapatkan hasil yang diinginkan. Setelah itu pengujian dilanjutkan dengan pengujian dari keseluruhan rangkaian komponen mikrokontroler yang telah terpasang. Pengujian yang akan dilakukan adalah :

- Pengujian LCD 16x2 karakter

- Pengujian program alat

\section{B. Pengujian LCD}

Pada tahap ini adalah pengujian komunikasi mikrokontroler arduino dengan LCD 16x2, pada alat ini lcd 16x2 digunakan sebagai monitor untuk mengetahui kondisi kerja sistem pemantauan lebih mudah. LCD 16x2 berfungsi untuk menampilkan text sesuai dengan program yang diberikan [13]. Berikut adalah hasil pengujian LCD

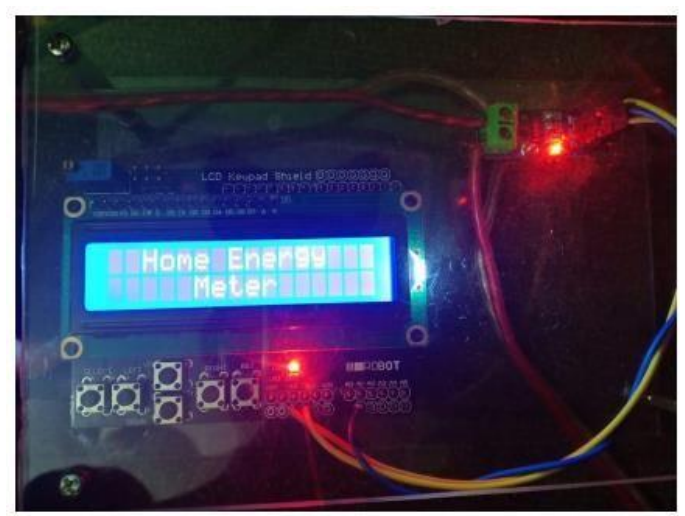

Gambar 8 Pengujian LCD

Pada Gambar 8, Setelah kode program telah di upload ke dalam arduino, lcd akan menampilkan tampilan seperti berikut.

Dan dapat dijelaskan ini adalah tampilan awal pada alat pantau yang saya buat. Dan kode program dapat dilihat pada Gambar 9 sebagai berikut :

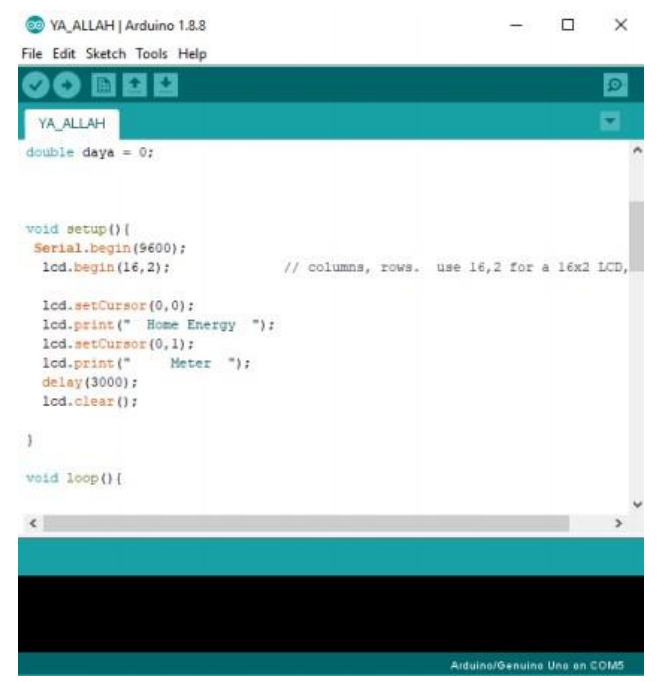

Gambar 9 Source Code LCD 


\section{Pengujian Program}

Tahapan selanjutnya adalah melakukan ujicoba sistem yang telah di buat apakah sudah dapat berjalan sesuai yang di inginkan [14]. Tahapan pengujian program sangat penting dilakukan agar alat berjalan sesuai dengan yang diinginkan. Tujuan dari pengujian ini adalah agar mengetahui letak kesalahan pada penulisan program dan tujuan dari alat tersebut. Program pada alat ini adalah sebagai berikut :

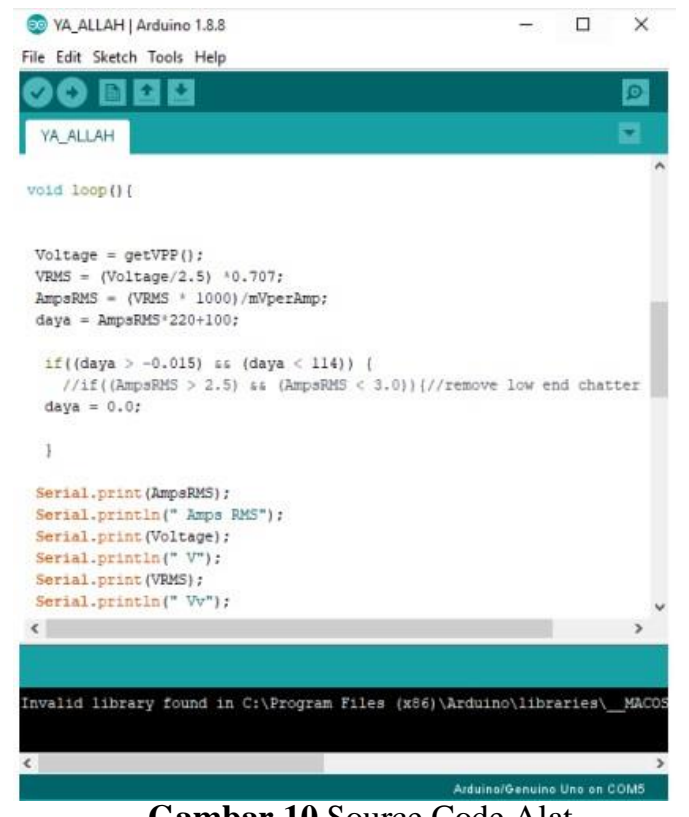

Gambar 10 Source Code Alat

Pada Gambar 10 diatas dapat dilihat isi dari program alat pantau tersebut.

Dan berikut adalah tampilan awal Lcd ketika masih dalam posisi belum menghitung suatu alat elektronik.

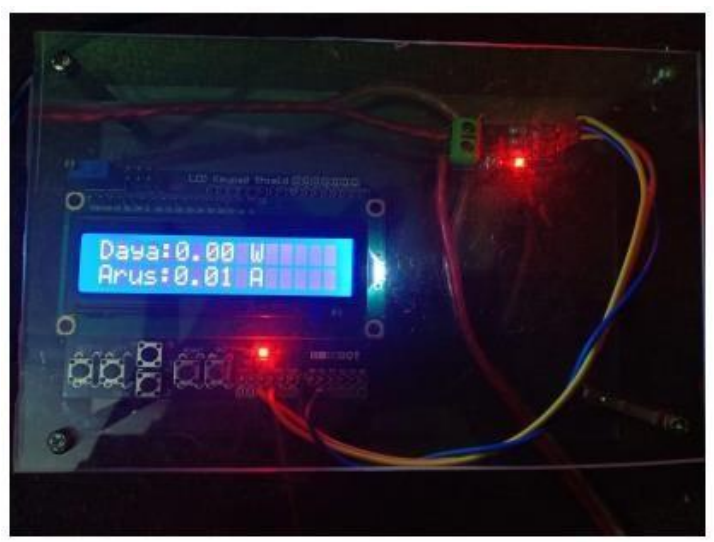

Gambar 11 Tampilan Awal

\section{Kesimpulan dan Saran}

Berdasarkan hasil penelitian maka dapat disimpulkan bahwa hasil dari penelitian sudah selesai dan hasil sudah dapat di uji coba dan sudah bisa digunakan. Tetapi masih banyak sekali kesalahan sistem karena perancangan dan program belum sempurna. Tetapi dalam proses melalukan penelitian sudah bisa dikatakan berhasil karena alat yang diharapkan dapat bekerja dengan semestinya walaupun belum sempurna seperti yang diharapkan. Dan diharapkan dapat dikembangkan oleh peneliti berikutnya. Setelah melalui tahap perancangan, pengujian dan pembahasan hasil pengujian secara keseluruhan maka dapat diambil beberapa kesimpulan yaitu perancangan alat monitoring berjalan dan bekerja dengan baik dan dapat menjalankan instruksi yang telah diprogramkan dan pembacaan nilai daya listrik bekerja dengan baik

\section{Daftar Pustaka}

[1] M. T. Andi Nurkholis, Agung Riyantomo, "Sistem Pakar Penyakit Lambung Menggunakan Metode Forward Chaining," Momentum, vol. 13, no. 1, pp. 32-38, 2017, doi: 10.1017/CBO9781107415324.004.

[2] A. Nurkholis and I. S. Sitanggang, "Optimization for prediction model of palm oil land suitability using spatial decision tree algorithm," J. Teknol. dan Sist. Komput., vol. 8, no. 3, pp. 192-200, 2020, doi: 10.14710/jtsiskom.2020.13657.

[3] I. H. Kurniawan and L. Hayat, "Perancangan Dan Implementasi Alat Ukur Tegangan, Arus Dan Frekuensi Listrik Arus Bolak-Balik Satu Fasa Berbasis Personal Computer," Techno, vol. 15, no. 1, pp. 21-31, 2014.

[4] D. Adityawarman, O. Zebua, and L. Hakim, "Rancang Bangun Alat Ukur Arus Menggunakan Transformator Arus Berbasis Mikrokontroler Atmega32," Electrician, vol. 8, no. 2, pp. 45-56, 2014.

[5] M. Arihutomo and M. Rivai, "Sistem Monitoring Arus Listrik Jala-Jala," J. Tek. Its, vol. 1, no. 1, pp. 150-153, 2012.

[6] B. G. Melipurbowo, "Pengukuran Daya Listrik Real Time Dengan Menggunakan Sensor Arus ACS712," Orbith, vol. 12, no. 1, pp. 17-23, 2016.

[7] S. Samsugi and A. Suwantoro, "Pemanfaatan Peltier dan Heater Sebagai Alat Pengontrol Suhu Air Pada Bak Penetasan Telur Ikan Gurame," Conf. Inf. Technol., pp. 295-299, 2018.

[8] D. Alita, S. Priyanta, and N. Rokhman, "Analysis of Emoticon and Sarcasm Effect on Sentiment Analysis of Indonesian Language on Twitter," $J$. Inf. Syst. Eng. Bus. Intell., vol. 5, no. 2, p. 100, 2019, doi: 10.20473/jisebi.5.2.100-109.

[9] Sulistiani, H., Miswanto, M., Alita, D., \& Dellia, P. (2020). Pemanfaatan Analisis Biaya Dan Manfaat Dalam Perhitungan Kelayakan Investasi Teknologi Informasi. Edutic-Scientific Journal of Informatics 
Education, 6(2).

[10] S. J. Sokop, D. J. Mamahit, M. Eng, and S. R. U. A. Sompie, "Trainer Periferal Antarmuka Berbasis Mikrokontroler Arduino Uno," E-Journal Tek. Elektro Dan Komput., vol. 5, no. 3, pp. 13-23, 2016, doi: 10.35793/jtek.5.3.2016.11999.

[11] R. I. Borman, K. Syahputra, P. Prasetyawan, and Jupriyadi, "Implementasi Internet Of Things pada Aplikasi Monitoring Kereta Api dengan Geolocation Information System," pp. 322-327, 2018.

[12] S. Utama, A. Mulyanto, M. Arif Fauzi, and N. Utami Putri, "Implementasi Sensor Light Dependent Resistor (LDR) Dan LM35 Pada Prototipe Atap Otomatis Berbasis Arduino," CIRCUIT J. Ilm. Pendidik. Tek. Elektro, vol. 2, no. 2, pp. 83-89, 2018, doi: 10.22373/crc.v2i2.3706.

[13] E. Saputro, "Rancang Bangun Pengaman Pintu Otomatis Menggunakan E-KTP Berbasis Mikrokontroler Atmega328," J. Tek. Elektro, vol. 8, no. 1, pp. 1-4, 2016.

[14] S. Samsugi, "IOT : EMERGENCY BUTTON SEBAGAI PENGAMAN UNTUK MENGHINDARI PERAMPASAN SEPEDA MOTOR," vol. 14, no. 2, pp. 100-106, 2020. 